\title{
Application of radio frequency inductively coupled plasma in chemical vapor deposition process of diamond-like carbon films for modification of properties of deposited films
}

\author{
WoJCIECH KiJASZEK*, WALDEMAR OLESZKIEWICZ, ZBIGNIEW ZNAMIROWSKI \\ Faculty of Microsystem Electronics and Photonics, Wrocław University of Science and Technology, Janiszewskiego 11/17, \\ 50-372 Wrocław, Poland
}

\begin{abstract}
The authors have deposited the diamond-like carbon (DLC) films by radio frequency inductively coupled plasma enhanced chemical vapor deposition (RF ICP PECVD) method. The investigated DLC films with different $\mathrm{sp}^{3}$ fraction content were deposited on polished and textured silicon substrates. The $\mathrm{sp}^{3}$ fraction content of the deposited DLC films was ranging from $35 \%$ to $70 \%$ and was estimated from acquired Raman scattering spectra (excitation wavelength: $325 \mathrm{~nm}$ and $514.5 \mathrm{~nm}$ ). The measurements of field emission characteristics were carried out in diode configuration. Emission properties of the DLC films were calculated from Fowler-Nordheim plots. The calculated electric field enhancement factor $\beta$ was ranging from 56 to 198 for the DLC films deposited on polished substrates and from 115 to 445 for films deposited on textured substrates. The surface of the DLC films was observed by scanning electron microscope (SEM) after field emission measurements. The acquired SEM images reveled that the activation of field emission from the DLC films is connected with generation of structural damage to the DLC films.
\end{abstract}

Keywords: diamond-like carbon; RF ICP PECVD; Raman scattering spectroscopy; field emission

\section{Introduction}

Over recent decades, synthesis and characterization of the diamond-like carbon (DLC) films have received major attention, due to their unique properties, such as high resistivity, thermal conductivity, mechanical hardness, chemical inertness, biocompatibility and field emissivity [1-5]. Mentioned properties make the DLC films an interesting material in electronics as passivation coatings, heat-sink layers and field emitters or in biology and medicine as protective coatings for implants, biosensors and biochips applications [1, 2, 6-10].

The properties of the DLC film strongly depend on the bonding configuration (relationship between $\mathrm{sp}^{3}$ and $\mathrm{sp}^{2}$ fraction content) of the film. Thanks to novel deposition techniques, such as radio frequency inductively coupled plasma enhanced

*E-mail: wojciech.kijaszek@pwr.edu.pl chemical vapor deposition (RF ICP PECVD), it is possible to deposit the DLC films with specific $\mathrm{sp}^{3}$ fraction content $[11,12]$.

The DLC films were investigated as a potential material for field emitter applications with low threshold electric field $[5,13]$. In the majority of works concerning the DLC films, the bonding configuration of the investigated DLC films is not specified. The field emission from DLC films was investigated by many researchers, e.g. Umehara et al. [14] have investigated DLC films deposited by microwave plasma CVD method and correlated $\mathrm{sp}^{2} / \mathrm{sp}^{3}$ bonding ratio (in relation to $\mathrm{G}$ band position) with emission properties of the DLC films.

The aim of the research is to investigate the emission properties of the DLC films with different bonding configurations and to correlate the emission properties with $\mathrm{sp}^{3}$ fraction content of the measured DLC film deposited by RF ICP PECVD methods. 


\section{Experimental}

The investigated DLC films were deposited by RF ICP PECVD method on silicon substrates [11, 12]. The films were deposited on polished and textured $10 \mathrm{~mm} \times 10 \mathrm{~mm}$ square silicon substrates located on 2" silicon transport plate. The silicon substrates were textured in wet etch process in $1 \mathrm{M}$ potassium hydroxide $(\mathrm{KOH})$ containing $2 \%$ isopropyl alcohol solution [15]. The surface of etched substrates was investigated by scanning electron microscope (SEM) observations (Fig. 1) and optical profilometer measurements.

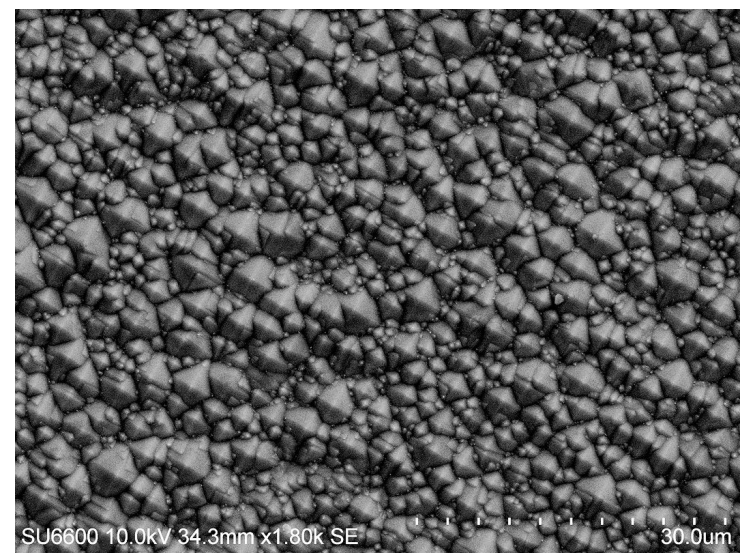

Fig. 1. SEM image of the surface of textured silicon substrate.

Three textured substrates with similar morphological properties were selected. The selection was based on the results of profilometric measurements, i.e. mean-square height $\left(\mathrm{S}_{\mathrm{q}} \sim 0.59 \mu \mathrm{m}\right)$ and mean-height of roughness profile elements $\left(\mathrm{R}_{\mathrm{c}} \sim 1.67 \mu \mathrm{m}\right)$. The results of profilometric measurements of polished substrates were as follows: $\mathrm{S}_{\mathrm{q}} \sim 6.3 \mathrm{~nm}$ and $\mathrm{R}_{\mathrm{c}} \sim 15.5 \mathrm{~nm}$.

During the RF ICP PECVD deposition process methane $\left(\mathrm{CH}_{4}\right)$ was supplied as a hydrocarbon precursor gas to the working chamber. The pressure in the working chamber $\mathrm{p}$ was maintained at $6.65 \mathrm{~Pa}$ and the methane flow rate was set at $100 \mathrm{sccm}$. The temperature of the table $\mathrm{T}$, on which the silicon substrate was located, was stabilized at $20^{\circ} \mathrm{C}$. The deposition of the DLC films was carried out at a constant power value of the RF $\left(\mathrm{P}_{\mathrm{RF}}\right)$ and ICP $\left(\mathrm{P}_{\mathrm{ICP}}\right)$ signals.
The DLC films with different bonding configurations ( $\mathrm{sp}^{3}$ around $35 \%, 50 \%$ and $70 \%$ ) were deposited on polished and textured substrates. The $\mathrm{sp}^{3}$ fraction content of the DLC films was controlled by the power value of the applied RF signal $[11,12]$. Before the deposition process, the silicon substrates were cleaned by ion bombardment in argon plasma discharge in order to improve the adhesion of the DLC film to the substrate. The thickness of the DLC films was $100 \mathrm{~nm}$.

The bonding configuration of the deposited DLC was verified by an analysis of Raman scattering spectra. The Raman scattering spectra of the investigated DLC films were acquired for samples excited by $514.5 \mathrm{~nm}$ laser radiation $\left(\mathrm{Ar}^{2+}\right.$ laser) and $325 \mathrm{~nm}$ laser radiation (Cd-He laser). In this work, the $\mathrm{sp}^{3}$ fraction content in the DLC films was calculated from the relationship between intensities of the $\mathrm{D}$ and $\mathrm{G}$ peaks $[1,16]$ and from the dispersion rate of the $G$ peak [17].

The field emission measurements were carried out in a system constructed by the Division of Vacuum and Plasma Technologies of Faculty of Microsystem Electronics and Photonics (Wrocław University of Science and Technology). The system had diode configuration and the anode was made from copper $(6 \mathrm{~mm}$ in diameter). During the measurements the sample was located in a vacuum chamber $\left(\sim 2.5 \times 10^{-4} \mathrm{~Pa}\right)$ and the distance between the sample and the anode was $25 \mu \mathrm{m}$. From the acquired current-voltage (I-V) characteristics, the current-electric field (I-E) and Fowler-Nordheim plots were calculated. The basic emission properties, such as enhancement of electric field factor $\beta$ and threshold electric field $E_{t h}$, were estimated from the acquired plots.

\section{Results}

According to the previous research, the $\mathrm{sp}^{3}$ fraction content of the DLC films is a function of applied RF power value [12]. The assumed $\mathrm{sp}^{3}$ fraction content of the DLC films was verified by Raman scattering spectroscopy measurements. The acquired spectra were fitted with double Gaussian peaks. The measurements confirmed 

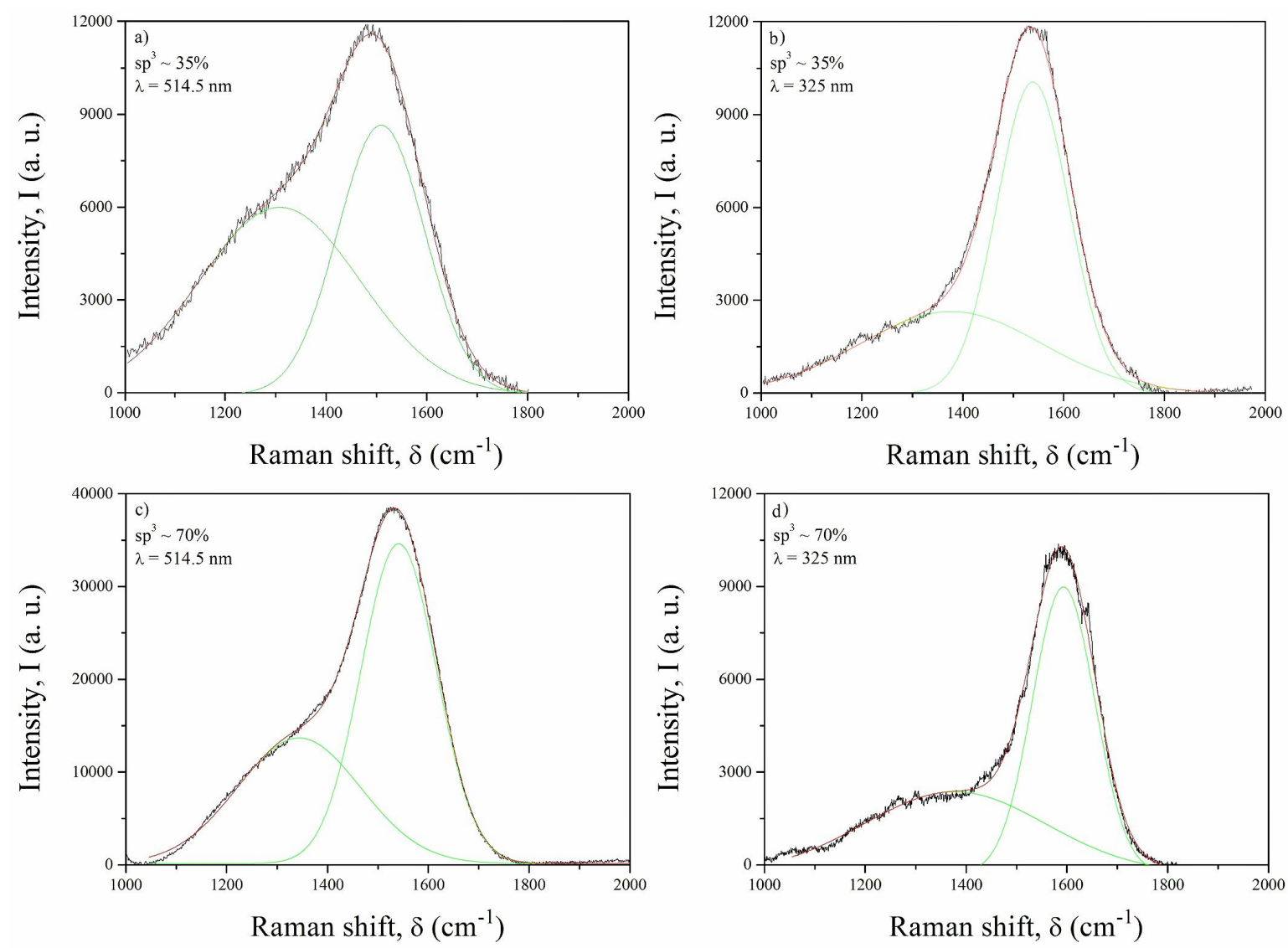

Fig. 2. Raman scattering spectra of the DLC film with (a) and (b) $35 \% \mathrm{sp}^{3}$ fraction content (Vis-Raman and UV-Raman); (c) and (d) $70 \% \mathrm{sp}^{3}$ fraction content (Vis-Raman and UV-Raman).

that the $\mathrm{sp}^{3}$ fraction content in the deposited DLC films is around $35 \%, 50 \%$ and $70 \%$. The Raman scattering spectra of the DLC films with $\mathrm{sp}^{3}$ fraction content around $70 \%$ and $35 \%$ are compared in Fig. 2.

The estimated values of $\mathrm{sp}^{3}$ fraction contents from the relationship between intensities of the D peak and the G peak are similar to the values calculated from the dispersion of the $G$ peak. Therefore, it is possible to assume that the calculated values are reliable. Examples of experimental data regarding dispersion rate of the $G$ peaks in Raman scattering spectra of the investigated DLC films are presented in the Table 1.

The field emission properties of the DLC films were measured in the system with diode configuration. The anode was mechanically cleaned and polished before measurements of each sample. Each
DLC film was measured four times (two times with increasing and two times with decreasing applied voltage between the anode and the sample). The IE characteristics and Fowler-Nordheim plot of the DLC film $\left(\mathrm{sp}^{3} \sim 70 \%\right.$ ) deposited on polished substrate are presented in the Fig. 3. The calculated emission parameters of the investigated DLC films are presented in the Table 2.

From the acquired results it follows that for the investigated DLC films, the electric field enhancement factor increases with the increase of the $\mathrm{sp}^{3}$ fraction content, while the threshold electric field value is minimal for the DLC films with $50 \%$ of the $\mathrm{sp}^{3}$ fraction content. The phenomenon could be explained by different bonding configurations of the DLC films. The experiment showed that it is possible to enhance emission properties of a structure by application of a DLC coating. 
Table 1. Position of G bands in the Raman scattering spectra of DLC films with different bonding configurations.

\begin{tabular}{cccc}
\hline $\begin{array}{c}\mathrm{sp}^{3} \\
{[\%]}\end{array}$ & $\begin{array}{c}\text { Pos(G) @ 325 } \mathrm{nm} \\
{\left[\mathrm{cm}^{-1}\right]}\end{array}$ & $\begin{array}{c}\text { Pos(G) @ 514.5 } \mathrm{nm} \\
{\left[\mathrm{cm}^{-1}\right]}\end{array}$ & $\begin{array}{c}\text { Disp(G) } \\
{\left[\mathrm{cm}^{-1} / \mathrm{nm}\right]}\end{array}$ \\
\hline \hline 35 & 1539.2 & 1507 & 0.17 \\
50 & 1553.6 & 1510 & 0.23 \\
70 & 1593.4 & 1537.4 & 0.3 \\
\hline
\end{tabular}
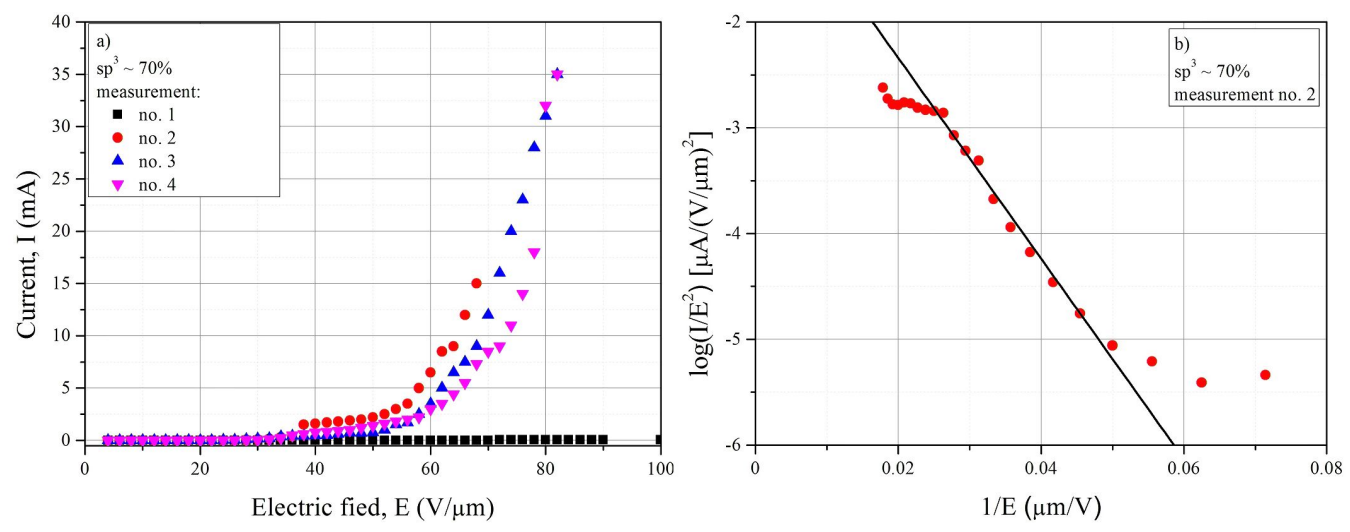

Fig. 3. Emission characteristics of the DLC film with $70 \% \mathrm{sp}^{3}$ fraction content: (a) I-E characteristics; (b) FowlerNordheim plot.

From the analysis of the measured I-E characteristics it follows that an activation of field emission from the investigated DLC films occurs after the first measurement. The activation mechanism could be connected with the generation of defects and damages created in the DLC films due to the presence of high electric field. After the initial activation, the field emission stabilizes until new defects are generated. The phenomenon is a result of dielectric breakdown of the film in high electric field and was conceived and described in the literature [18]. The theory was confirmed by the scanning electron microscope investigation of the surface of the DLC films, carried out after the I-V measurements. The generated defects/damages have different form (erosion, delamination, melting) and their form depends on the $\mathrm{sp}^{3}$ fraction content of the deposited DLC film. The SEM images of the generated defects are presented in Fig. 4.

\section{Conclusions}

The aim of the research was to investigate the relationship between bonding configuration and emission properties of the DLC films.
The diamond-like carbon films with different $\mathrm{sp}^{3}$ fraction content were deposited by RF ICP PECVD method on polished and textured silicon substrates.

The $\mathrm{sp}^{3}$ fraction content of the deposited DLC films was verified by Raman scattering spectroscopy. The investigated DLC films had $35 \%$, $50 \%$ and $70 \% \mathrm{sp}^{3}$ fraction content.

The carried out research showed that the bonding configuration has an influence on the emission properties of the DLC film. The highest values of electric field enhancement factor were achieved for the DLC films with the highest $\mathrm{sp}^{3}$ fraction content, i. e. 198 and 445 for the DLC films deposited on polished and textured substrates, respectively. The DLC films with $50 \% \mathrm{sp}^{3}$ fraction content were characterized by the lowest value of the threshold electric field. The acquired results are comparable with the data found in the literature [14]. For specific application, the bonding configuration of the applied DLC films should be optimized for achieving specific emission parameters.

The SEM investigation showed that the activation of field emission from the DLC films is 
Table 2. Calculated emission parameters of the investigated DLC films.

\begin{tabular}{lcccc}
\hline \multicolumn{3}{c}{ DLC films deposited on polished substrates } \\
\hline $\begin{array}{c}\text { electric field } \\
\mathrm{sp}^{3}(\%)\end{array}$ & $\begin{array}{c}\text { DLC films deposited on textured substrates } \\
\text { enhancement factor } \\
(\beta)\end{array}$ & $\begin{array}{c}\text { threshold electric } \\
\text { field }\left(\mathrm{E}_{\mathrm{th}}-\mathrm{V} / \mu \mathrm{m}\right)\end{array}$ & $\begin{array}{c}\text { enhancement factor } \\
(\beta)\end{array}$ & $\begin{array}{c}\text { threshold electric } \\
\text { field }\left(\mathrm{E}_{\mathrm{th}}-\mathrm{V} / \mu \mathrm{m}\right)\end{array}$ \\
\hline \hline 35 & 56 & 92.6 & 115 & 66.7 \\
50 & 170 & 20 & 336 & 12.4 \\
70 & 198 & 27.5 & 445 & 19.6 \\
\hline
\end{tabular}
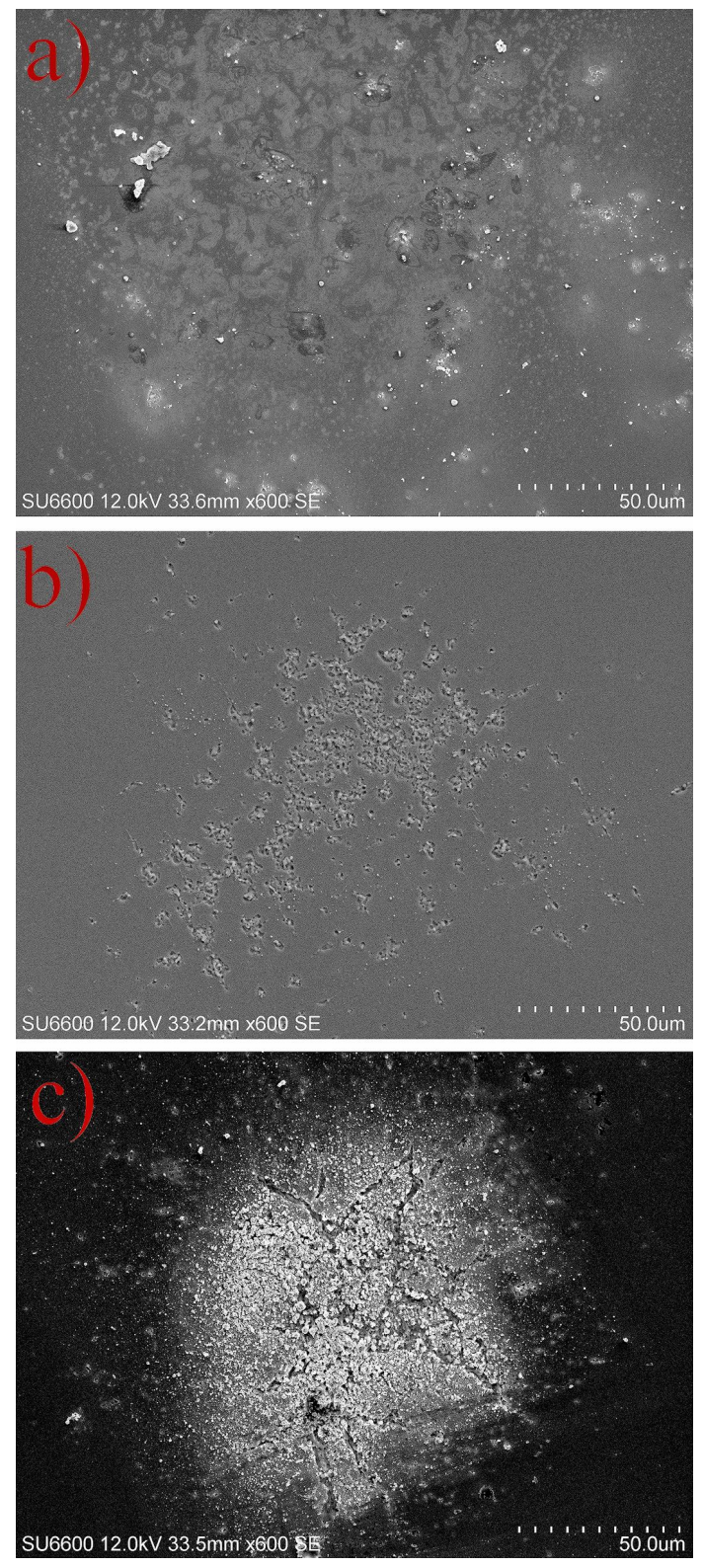

Fig. 4. SEM images of damages generated by field emission in the DLC films with (a) $35 \%$; (b) $50 \%$; (c) $70 \% \mathrm{sp}^{3}$ fraction content. connected with defects generation, which results in damages of the film. Further investigation of the observed damages (for example by energy dispersive X-ray spectroscopy) is required for explanation of differences in their formation.

Due to the nature of the field emission from the DLC films, it is necessary to investigate the reliability and long-term stability of the field emission from the DLC films by reduction of generated defects.

\section{Acknowledgements}

This work was co-financed by the European Union within the European Regional Development Fund, through the Grant Innovative Economy (POIG.01.01.02-00-008/08-05) and by the Wroclaw University of Science and Technology Statutory Grants. The Project "Interuniversity Didactic-Technological Center 'TECHNOPOLIS' in Wrocław" co-funded by the European Union from the funds of the European Regional Development Fund under the Infrastructure and Environment Program No. UDA-POIS.13.01-021/09-00 is acknowledged for SEM images. The authors would like to thank Prof. Irena Zubel for texturization of silicon substrates and Prof. Jaroslav Kovăč Jr. for Raman scattering spectroscopy measurements.

\section{References}

[1] Robertson J., Mat. Sci. Eng. B-Adv., 37 (2002), 129.

[2] Donnet C., ERdemir A., Tribology of DiamondLike Carbon Films: Fundamentals and Applications, Springer, 2008.

[3] Tomozeiu N., Hart A., Kleinsorge B., Milne W.I., Diam. Relat. Mater., 8 (1999), 522.

[4] Hauert R., Diam. Relat. Mater., 12 (2003), 583.

[5] Groning O., Kuttel O.M., Groning P., SchlapBACH L., Appl. Surf. Sci., 111 (1997), 135.

[6] Robertson J., Phys. Status Solidi A, 205 (9) (2008), 2233.

[7] Bewilogua K., Hofmann D., Surf. Coat. Tech., 242 (2014), 214.

[8] Horng R.H., Kao W.C., Ou S.L., WuU D.S., Appl. Phys. Lett., 101 (2012), 171102.

[9] Dearnaley G., Arps J. H., Surf. Coat. Tech., 200 (2005), 2518. 
[10] Gronau R., Szmidt J., Firek P., Czerwosz E., JARZYŃSKA D., STARYGA E., Vacuum, 82 (2008), 962.

[11] Oleszkiewicz W., Markowski J., SRnanek R., KiJASZeK W., GRYGlewicz J., KovăČ J., TŁacZaŁa M., Opt. Appl., 43 (1) (2013), 109.

[12] Oleszkiewicz W., Kijaszek W., Gryglewicz J., Zakrzewski A., Gajewski K., Kopiec D., KamyCZeK P., Popko E., TŁaczaŁa M., Proc. SPIE, 8902 (2013), 89022H.

[13] Lee K.R., Eun K.Y., Lee S., Jeon D.R., Thin Solid Films, 290 - 291 (1996), 171.

[14] Umehara Y., Murai S., Koide Y., Murakami M., Diam. Relat. Mater., 11 (2002), 1429.
[15] Zubel I., Granek F., Rola K., Banaszczyk K., Appl. Surf. Sci., 258 (22) (2012), 9067.

[16] Shi J.R., Shi X., Sun Z., LaU S.P., TAY B.K., TAN H.S., Diam. Relat. Mater., 10 (2001), 76.

[17] Cui W.G., Lai Q.B., Zhang L., Wang F.M., Surf. Coat. Tech., 205 (2010), 1995.

[18] Inomoto H., Hatta A., Kawabata K., Katoda T., Hiraki A., Diam. Relat. Mater, 9 (2000), 1209.

Received 2017-04-03 Accepted 2018-01-24 